\title{
Current-Voltage Modeling of the Enzymatic Glucose Fuel Cells
}

\author{
Vladimir Zeev Rubin \\ SciRCon (Scientific, Research, Consulting), Los Angeles, USA \\ Email: rubin_zeev@yahoo.com
}

Received 8 February 2015; accepted 26 March 2015; published 1 April 2015

Copyright (C) 2015 by author and Scientific Research Publishing Inc.

This work is licensed under the Creative Commons Attribution International License (CC BY). http://creativecommons.org/licenses/by/4.0/

(c) () D Den Access

\section{Abstract}

Enzymatic fuel cells produce electrical power by oxidation of renewable energy sources. An enzymatic glucose biofuel cell uses glucose as fuel and enzymes as biocatalyst, to convert biochemical energy into electrical energy. The applications which need low electrical voltages and low currents have much of the interest in developing enzymatic fuel cells. An analytical modelling of an enzymatic fuel cell should be used, while developing fuel cell, to estimate its various parameters, to attain the highest power value. In this paper an analytical model for enzymatic glucose membraneless fuel cell with direct electron transfer was developed. The adequacy of the model was estimated by comparison with fuel cells parameters. The electrical characteristics of fuel cells are interpreted using this model, based on theoretical consideration of ions transportation in solution. The influence of the hydrogen ions, glucose and enzyme concentration and also a thickness of enzyme layer on electrical parameters of a fuel cell were investigated. The electrical parameters such as a current, a voltage, a power were calculated by the model, for various parameters of the fuel cells. The model aimed to predict a hydrogen ions current, an electrical voltage and an electrical power in enzymatic fuel cell with direct electron transfer. The model reveals that increasing the rates of hydrogen ions generation and consumption leads to higher value of current, voltage and power.

\section{Keywords}

Enzyme, Biofuel Cell, Glucose, Modeling, Power, Current

\section{Introduction}

The glucose fuel cells use glucose as a fuel to produce electrical energy [1]-[5], and they use enzymes as biocatalyst to convert directly chemical or biochemical energy into electrical energy [6]-[9]. Enzymatic catalysts for 
glucose fuel cells have excellent selectivity and can generate power densities of the order of several $\mathrm{mW} \cdot \mathrm{cm}^{-2}$ [10] [11]. Finally, in glucose enzymatic fuel cells enzymes convert the glucose into water and carbon dioxide. Modelling biofuel cells play important role in understanding and developing new devices. The enzymatic fuel cells mathematical models are based on a system of non-linear equations, including reaction kinetics, transport phenomena [12] [13], statistical analysis [14], metabolic analysis [15]. There is a single channel [12] for flow of each anolyte and catholyte streams. An exponential decay in the availability of oxygen from the cathode side was observed [16] [17]. Various authors have used theoretical numerical and experimental methods for estimating the fuel cell performance [18]-[21]. Majority of modelling are numerical and based on mediator electron transfer mechanism and membrane used fuel cells [7] [21] [22]. The focus of this paper is to develop a theoretical analytical model for enzymatic membraneless glucose fuelled fuel cell, with direct electron transfer and enzymes are immobilized on an electrode surface. The present study aimed to predict a hydrogen ions current, an electrical voltage and an electrical power in enzymatic fuel cells, based on basic chemical and electro physical principles.

\section{Theory}

In general, biofuel cells transfer electrons to an electrode either directly (direct electron transfer) or through mediator molecules (mediated electron transfer) [23]. The model presented here bases on experimental results with direct electron transfer fuel cell that were reported at [8]. The model includes two parallels plane each other electrodes. Electrodes are separated by a membraneless reservoir, between electrodes, containing an electrolyte (phosphate buffer) solution, enables ions movement between the electrodes. The fuel reservoir with a glucose solution is positioned left to the anode.The electrodes consisted of carbon cloth with gold or silver. The enzymes (glucose oxidase) are immobilized to an anode. The electrochemical reaction is the oxidation of glucose to gluconic acid gives two electrons and two protons [24]. Hydrogen ions generated on the anode and move from the anode to the cathode through the liquid bulk. The cathode is exposed to air and the porous cathode allows oxygen to pass. On the cathode, oxygen reacts chemically with the electrons from the external circuit and with the hydrogen ions from the electrolyte to yield water [8]. Michaelis-Menten equation [25] for rate of a volume hydrogen ions generation $g_{01}$ was adapted [8] to surface $g_{1 s}$ (Equation (1)) hydrogen ions generation

$$
g_{1 S}=k_{\text {cat }}\left[E_{s}\right][G] /\left(K_{M}+[G]\right)
$$

It gives the surface reaction rate $g_{1 S}$ as a function of glucose concentration [G] and a surface enzyme concentration $\left[E_{S}\right]$. Here the kinetic enzyme reaction rates are $k_{c a t}$ and $K_{M}$. Note, that a connection between [ $E_{S}$ ] and volume enzyme concentration $\left[E_{T}\right]$ can be taken as $\left[E_{S}\right]=L\left[E_{T}\right]$, where $L$ is a thickness of an enzyme layer.

\subsection{Mathematical Model}

Enzymatic anode. The model is assumed to be in steady state in regards to proton production and consumption. Enzymes are immobilized homogeneously and can be directly oxidized on the electrode surface. An enzyme layer has a uniform thickness. A buffer solution is assumed to be electrically neutral. Hydrogen ions, generated on an anode, are moving towards a cathode, were they are consumed. A current density is assumed here to be one dimensional along the $\mathrm{x}$-axis. The axis $x$ is normal to both of electrodes. The point $x=0$ on an axis $\mathrm{x}$ represents the surface between the enzymatic anode and a glucose reservoir, $x=L$ is the boundary between the enzymatic anode and the buffer solution, $x=d$ is the boundary between the buffer solution and the cathode. The thickness of the cathode doesn't take into consideration in this paper. The kinetics and mass transport in the enzyme layer $(0<x<L)$ can be represented as follow differential equations for hydrogen ions (Equation (2)), that describes concentration changes as a function of the distance:

$$
D_{H^{+}} \frac{\mathrm{d}^{2} C_{H^{+}}}{\mathrm{d} x^{2}}+\frac{2 k_{c a t}\left[E_{T}\right][G]}{K_{M}+[G]}=0
$$

and for glucose

$$
D_{G} \frac{\mathrm{d}^{2}[G]}{\mathrm{d} x^{2}}-\frac{2 k_{c a t}\left[E_{T}\right][G]}{K_{M}+[G]}=0
$$


where $D_{G}, D_{H^{+}}$are diffusion coefficients of glucose and hydrogen ions respectively, $c_{H^{+}}$is hydrogen ions concentration

\subsection{Bulk Solution}

In the bulk $(L<x<d)$ the mass conservation equation of solute species in a steady state conditions for the current density of hydrogen ions $j_{H^{+}}$converts to form (4):

$$
j_{H^{+}}=-e D_{H^{+}} \frac{\mathrm{d} c_{H^{+}}}{\mathrm{d} x}+e \frac{F D_{H^{+}} c_{H^{+}}}{R T} E
$$

Here $e$ signed electron ionic charge, $E$ is an electrical field, $F$-Faraday constant, $R$ - universal gas constant, $T$-temperature.

$j_{H^{+}}$is a current density of ions present in the solution during the fuel cell operations. The total current density $j$ is made up of contribution from all species.

Outside the enzyme layer in the bulk $(L<x<d)$ the hydrogen ions behaviour if the only diffusion takes place can be expressed by the Equation (5).

$$
D_{H^{+}} \frac{\mathrm{d}^{2} c_{H^{+}}}{\mathrm{d} x^{2}}=0
$$

The solution these Equations (2) (3) (5) gives hydrogen concentration along axis $x$ which finally uses to calculate a voltage and a power of a fuel cell.

\subsection{Boundary Conditions}

The boundary conditions between two regions mean the equal species fluxes through the same surface and conditions of a continuity for concentrations. The diffusion coefficients of hydrogen ions are different in these two regions. Equations (6) (7) describe the following boundary conditions between the anode and the bulk where $x=$ $L$ for hydrogen ions:

$$
\begin{aligned}
\left.D_{H^{+}} \frac{\mathrm{d} c_{H^{+}}}{\mathrm{d} x}\right|_{x=L}=\left.D_{b H^{+}} \frac{\mathrm{d} c_{H^{+}}}{\mathrm{d} x}\right|_{x=L} \\
\left.c_{H^{+}}\right|_{x=L}=\left.c_{H^{+}}\right|_{x=L}
\end{aligned}
$$

where $D_{b H^{+}}$are diffusion coefficients of hydrogen ions in the bulk solution.

The concentration of the hydrogen ions at the anode surface where $x=0$ was taken

$$
\left.c_{H^{+}}\right|_{x=0}=c_{0}
$$

where $c_{0}$ is the hydrogen ions concentration between the glucose reservoir and an anode. The concentration of glucose at an anode surface $(x=0)$ was taken as:

$$
\left.[G]\right|_{x=0}=\left[G_{0}\right]
$$

where $\left[G_{0}\right]$ is the glucose concentration in the glucose reservoir. The current density is proportional to rate of an electrochemical reaction of a unit surface electrode. An amount of charge is proportional to the amount of material passed through the interface. This yields for another boundary condition

$$
\mathrm{d}[G] /\left.\mathrm{d} x\right|_{x=0}=-g_{1 S} / z D_{G}
$$

Here $z$ expressed the number of elementary ionic charges. Boundary conditions for cathode at a point $x=d$ defined as:

$$
\left.c_{H^{+}}\right|_{x=d}=c_{d}
$$

or 


$$
\left.D_{b H^{+}} \frac{\mathrm{d} c_{H^{+}}}{\mathrm{d} x}\right|_{x=d}=-g_{S 2}
$$

where $c_{d}$ is the hydrogen ions concentration between the electrolyte reservoir and cathode, $g_{2 S}$ is a rate of surface hydrogen ions consumption on a cathode surface.

\subsection{Hydrogen Ions Concentration}

The solution Equation (3) when $[G] \gg k_{M}$ with boundary conditions $(9,10)$ gives glucose concentration along axis $x$ in a region $0<x<L$. (Note, than $k_{M}=0.019 \mathrm{M},[G]=1 \mathrm{M}$ [8]) Substituting this solution into the differential Equation (2) for hydrogen ions in a region $(0<x<L)$ yields follow Equation (13)

$$
D_{H^{+}} \frac{\mathrm{d}^{2} c_{H^{+}}}{\mathrm{d} x^{2}}+\frac{2 k_{c a t}\left[E_{T}\right]\left(\frac{k_{c a t}\left[E_{T}\right]}{D_{G}} \frac{x^{2}}{2}-\frac{k_{c a t}\left[E_{T}\right]}{D_{G}} \frac{L}{2} x+\left[G_{0}\right]\right)}{k_{M}+\frac{k_{c a t}\left[E_{T}\right]}{D_{G}} \frac{x^{2}}{2}-\frac{k_{c a t}\left[E_{T}\right]}{D_{G}} \frac{L}{2} x+\left[G_{0}\right]}=0
$$

From Equations (5) (13) with boundary conditions $(6,7,8,11)$ the hydrogen ions concentration in region $(0<$ $x<L$ ) can be obtain as:

$$
\begin{aligned}
c_{H^{+}}= & -\frac{k_{c a t}\left[E_{T}\right]}{2 D_{H^{+}}} x^{2}+x\left(\frac{k_{c a t}\left[E_{T}\right] L^{2}}{D_{H^{+}}}\left(\frac{1}{2}-\frac{D_{H^{+}}}{D_{b H^{+}}}\right)\right. \\
& \left.+\frac{k_{c a t}\left[E_{T}\right] L d}{D_{H^{+}}} \frac{D_{H^{+}}}{D_{b H^{+}}}+c_{d} \frac{D_{H^{+}}}{D_{b H^{+}}}\right) /\left(\frac{D_{H^{+}}}{D_{b H^{+}}}(d-L)+L\right)
\end{aligned}
$$

And hydrogen ions concentration in a bulk $(L<x<d)$ yields (Equation (15)):

$$
\begin{aligned}
c_{H^{+}}= & c_{d}+(d-x) \cdot\left\{\frac { \frac { D _ { H ^ { + } } } { D _ { b H ^ { + } } } } { \frac { D _ { H ^ { + } } } { D _ { b H ^ { + } } } ( d - L ) + L } \left(-\frac{k_{c a t}\left[E_{T}\right] L^{2}}{D_{H^{+}}}\left(\frac{1}{2}-\frac{D_{H^{+}}}{D_{b H^{+}}}\right)\right.\right. \\
& \left.\left.-\frac{k_{c a t}\left[E_{T}\right] L d}{D_{H^{+}}} \frac{D_{H^{+}}}{D_{b H^{+}}}-c_{d} \frac{D_{H^{+}}}{D_{b H^{+}}}\right)+\frac{k_{c a t}\left[E_{T}\right] L}{D_{H^{+}}} \frac{D_{H^{+}}}{D_{b H^{+}}}\right\}
\end{aligned}
$$

\subsection{Current}

The current is the flux at the electrode surface, that is a current density of a fuel cell yields

$$
j=z F D_{H^{+}} \mathrm{d} c_{H^{+}} /\left.\mathrm{d} x\right|_{x=0}
$$

Since a flux at the electrode surface where $x=0$ caused by the rate $g_{1 S}$ of hydrogen ions generation from an anode surface per unit of time the appropriate equation for gradient can be written as:

$$
\mathrm{d} c_{H^{+}} /\left.\mathrm{d} x\right|_{x=0}=-g_{1 S} / z D_{H^{+}}
$$

Substituting Equations (1) (17) into Equation (16) yields

$$
j=z F\left(k_{c a t}\left[E_{T}\right][G] L\right) /\left(K_{M}+[G]\right)
$$

The Equation (18) reveals that a current density is proportional to a rate of electrochemical reactions $k_{c a t}$ in a fuel cell, enzyme concentrations and a thickness of enzyme layer. In case of direct electron transfer increases 
number of electrons involved in reactions linearly increases a current density. It means that electrical characteristics of fuel cells can be significantly improved by using some types of enzyme catalyst that diverted more than two electrons to the electrode.

Actually, the current can be computed as well from the hydrogen ions concentration (Equation (14)):

$$
\begin{aligned}
j= & \left.z F D_{H^{+}} \frac{\mathrm{d} c_{H^{+}}}{\mathrm{d} x}\right|_{x=0}=z F D_{H^{+}}\left(\frac{k_{c a t}\left[E_{T}\right] L^{2}}{D_{H^{+}}}\left(\frac{1}{2}-\frac{D_{H^{+}}}{D_{b H^{+}}}\right)\right. \\
& \left.+\frac{k_{c a t}\left[E_{T}\right] L d}{D_{H^{+}}} \frac{D_{H^{+}}}{D_{b H^{+}}}+c_{d} \frac{D_{H^{+}}}{D_{b H^{+}}}\right) /\left(\frac{D_{H^{+}}}{D_{b H^{+}}}(d-L)+L\right)
\end{aligned}
$$

When a value of glucose concentration $[G]$ is much greater than $k_{M}$ both Equations (18) (19) reduce (with $D_{H^{+}} / D_{b H^{+}}=0.5$ ) to the simple form

$$
j=z F k_{\text {cat }}\left[E_{T}\right] L
$$

This yields the same value of a calculated current in both cases. These equations suggest clear ways to achieve increasing a current density and as a consequence an electrical power density: increase $k_{\text {cat }}$, thickness of an enzymatic layer $L$ and a total enzyme concentration $\left[E_{T}\right]$.

\subsection{Electrical Power}

In general a power $P$, for an electrical circuit with an external load resistance $R_{L}$ and with electrical source $\Delta V$, which has an internal electrolyte resistance $r_{O}$ resistance between electrodes, can be expressed as

$$
P=I^{2} R_{L}
$$

where $I$ is the current that equals to

$$
I=\Delta V /\left(R_{L}+r_{0}\right)
$$

Difference potentials of electrical source $\Delta V$ for high hydrogen ions concentration estimated by Equations (4) (15) lead to

$$
\Delta V=-\int_{L}^{d} E \mathrm{~d} x=-\frac{R T}{F} \ln \frac{c_{L}}{c_{d}}
$$

The result is similar to [8]. Here $c_{L}$ is the hydrogen ions concentration at the point $x=L$ between the anode and electrolyte reservoir. Many factors are affecting losses in a fuel cell: mass transfer, electron transfer, chemical reactions, surface reactions etc. [26]. If take into consideration these factors and Equations (21)-(23) an power density $\bar{P}$ of a fuel cell can be expressed in a follow form:

$$
\bar{P}=\left(\frac{R T}{A F} \ln \frac{c_{d}}{c_{L}}\right)^{2} /\left(R_{L}+2 \sum r_{i}+\frac{\sum r_{i}^{2}}{R_{L}}\right)
$$

where $A$ is an anode area, $r_{i}[\mathrm{Ohm}]$ represents resistances of losses in a fuel cell like electrode reaction resistances, mass transfer, charge transfer etc. This expression shows, as expected, that minimizing the electrolyte resistance and the others resistance of losses in a fuel cell is essential way to increase a power. The maximal power density $\bar{P}$ can be estimated by using Equations (19) and (23), that is:

$$
\bar{P}=z R T k_{c a t}\left(\ln \frac{c_{L}}{c_{d}}\right)\left[E_{T}\right][G] L /\left(K_{M}+[G]\right)
$$

\section{Results and Discussion}

\subsection{Model Parameters}

The system of equations that described above was solved using the program Mathematica 8. The parameters are 
using to validate this model (except the Section 3.3) were measured by [8]: the temperature $23^{\circ} \mathrm{C}$, the distance between electrodes $d$ was $0.003-0.004 \mathrm{~m}$. The thickness of an enzyme layer $L$ was estimated $0.001-0.0005 \mathrm{~m}$, the glucose concentration $[G]=1 \mathrm{M},\left[E_{T}\right]=10^{-6}-10^{-5} \mathrm{M}, k_{M}=0.019 \mathrm{M}, k_{c a t}=10^{3} \mathrm{sec}^{-1}$, the hydrogen ion diffusion coefficient in water was taken as $4.5 \times 10^{-9} \mathrm{~m}^{2} / \mathrm{sec}$ [20]. The ratio $D_{H^{+}} / D_{b H^{+}}$between diffusion coefficients $D_{H^{+}}$in an area $0<x<L$ and $D_{b H^{+}}$in a bulk $L<x<d$ varies. There is $D_{H^{+}} / D_{b H^{+}}=0.5,0.8,1$ for different calculations.

\subsection{Hydrogen Ions Concentration}

Generated hydrogen ions are moving towards cathode and consuming there. During this process a gradient of hydrogen ions exists between the electrodes in a region $L<x<d$. A voltage, a current density and an electrical power of fuel cells depend on concentrations and a gradient of hydrogen ions. Therefore it is important to evaluate concentrations and a gradient of hydrogen ions in a fuel cell. The hydrogen ions concentration in the region $0<x<L$ was calculated by Equation (14). The concentrations as a function of the distance $x$, when $0<x<L$ (Figure 1) are plotted for different diffusion coefficients of hydrogen ions and different values of total enzyme concentrations.

Figure 1: The concentration of hydrogen ions $(M)$ in a region $(0<x<L)$ (Equation (14)) is plotted against $x$ for different total enzyme concentrations $\left[E_{T}\right] . \quad L=10^{-3} \mathrm{~m}, D_{H^{+}} / D_{b H^{+}}=0.8$. Lines from top to the bottom $\left[E_{T}\right]=0.7 \times 10^{-5} \mathrm{M}, 0.5 \times 10^{-5} \mathrm{M}, 0.3 \times 10^{-5} \mathrm{M}, 0.1 \times 10^{-5} \mathrm{M}$ respectively.

Figure 1 demonstrates that the hydrogen ions concentration depends of a ratio $D_{H^{+}} / D_{b H^{+}}$hydrogen ions diffusion coefficients. The hydrogen ions concentration increases with this ratio and a total enzyme concentration. A thickness of enzyme layer and an enzyme concentration influences on the boundary concentration $c_{L}$ and as a consequences on a voltage and a power.The hydrogen ions concentration in a bulk $L<x<d$ was calculated by Equation (15). The hydrogen ions concentrations in a bulk as a function of the distance $x$, when $L<x<d$ (Figure 2), are plotted for different ratio of diffusion coefficients and different values of a total enzyme concentration.

Figure 2: The concentration of hydrogen ions $(M)$ in a bulk (region $L<x<d$ ) (Equation (15)) is plotted against $x$ for different total enzyme concentrations $\left[E_{T}\right] . \quad L=10^{-3} \mathrm{~m}, D_{H^{+}} / D_{H^{+}}=0.8$. Lines from top to the bottom $\left[E_{T}\right]=0.7 \times 10^{-5} \mathrm{M}, 0.5 \times 10^{-5} \mathrm{M}, 0.3 \times 10^{-5} \mathrm{M}, 0.1 \times 10^{-5} \mathrm{M}$ respectively, $d=4 \times 10^{-3} \mathrm{~m}$.

Figure 2 demonstrates that the hydrogen ions concentrations in the bulk also depend of a ratio hydrogen ions diffusion coefficients $D_{H^{+}} / D_{b H^{+}}$and growing with it. The hydrogen ions concentration in the bulk increases with a total enzyme concentration. The gradient of hydrogen ions changes with a boundary concentration $c_{d}$. Actually, the main factors that determine a hydrogen ions gradient in fuel cells are type electrodes in used, the

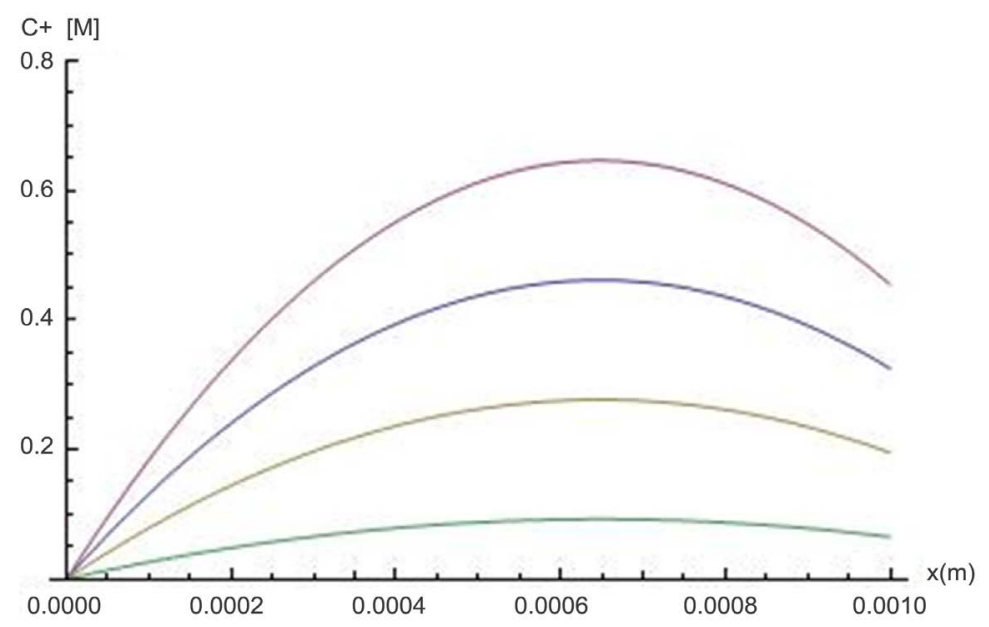

Figure 1. The concentration of hydrogen ions $(M)$ in a region $(0<\mathrm{x}<\mathrm{L})$ (Equation (14)) is plotted against $x$ for different total enzyme concentrations $\left[E_{T}\right] . \quad L=10^{-3} \mathrm{~m}, D_{H^{+}} / D_{b H^{+}}=0.8$. Lines from top to the bottom $\left[E_{T}\right]=0.7$ $\times 10^{-5} \mathrm{M}, 0.5 \times 10^{-5} \mathrm{M} 0.3 \times 10^{-5} \mathrm{M} 0.1 \times 10^{-5} \mathrm{M}$ respectively. 


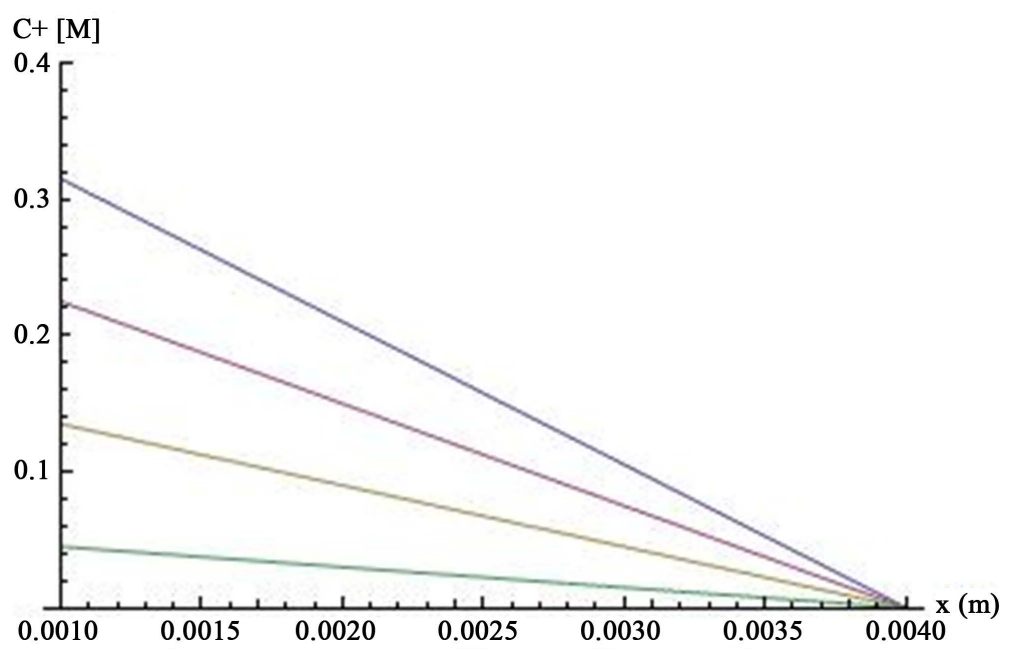

Figure 2. The concentration of hydrogen ions $(M)$ in a bulk (region $L<x<d$ ) (Equation (15)) is plotted against $x$ for different total enzyme concentrations $\left[E_{T}\right] . L=10^{-3} \mathrm{~m}, d=4 \times 10^{-3} \mathrm{~m}, D_{H^{+}} / D_{H^{+}}=0.8$. Lines from top to the bottom $\left[E_{T}\right]=0.7 \times 10^{-5} \mathrm{M}, 0.5 \times 10^{-5} \mathrm{M}, 0.3 \times 10^{-5} \mathrm{M}, 0.1 \times 10^{-5} \mathrm{M}$ respectively.

total enzyme concentration, a thickness of enzyme layer and basic kinetic parameters. As a result, they determine an electrical power of a fuel cell.

\subsection{Current Density and Electrical Power}

Glucose fuel cell with glucose oxidase enzymatic filter paper was described in [6] ([G] = $10 \mathrm{mM}$, buffer phosphate, obtained typical current density range $(5-20) \mu \mathrm{A} / \mathrm{cm}^{2}$ and open circuit voltage around $\left.0.18 \mathrm{~V}\right)$. Carbon nanotubes serve to promote conduction and help immobilize the enzymes. Design was simplified by removing membrane. We think the represented here model can explain these experimental results. The dependence current density on enzyme concentration and an enzyme layer thickness was obtained from expression (19) (Figure 3). The effect of enzyme concentration and an enzyme layer thickness is linear with a current density, hence increasing either enzyme concentration and enzyme layer thickness has an important effect on the fuel cell.

Lines from top to the bottom glucose concentration $[G]=0.1 \mathrm{M}, 0.01 \mathrm{M}, 0.001 \mathrm{M}$ respectively, total enzyme concentration $E_{T}=10^{-5} \mathrm{M}, 0.5 \times 10^{-5} \mathrm{M}, 10^{-6} \mathrm{M}$ respectively.Calculations reveal that current density increases with a glucose concentration. For very low glucose concentration below $0.01 \mathrm{M}$ changing of a current density is almost linear with glucose concentration.

Eventually, according to Equation (19), a saturated value of a current density is independent of further increasing in glucose concentration. The maximal power density $\bar{P}$ was calculated by Equation (25) when $j=$ (5 - 20) $\mu \mathrm{A} / \mathrm{cm}^{2}$ and voltage around $0.18 \mathrm{~V}$. This gives range about $0.9-4 \mu \mathrm{W} / \mathrm{cm}^{2}$. Calculated values of a current density and a power density have a good agreement with measurements [6]. Power density $\bar{P}$ decreases, after achieved a max value, with rising an external resistance and as consequence of a current reduction (Figure 4).

Lines from top to the bottom a relation is $c_{L} / c_{d}=5 \times 10^{3}, 50$ respectively.Because a fuel cell [6] has a very small current, $\Delta V$ is orders of magnitude higher than the most of the other losses.If an external resistance increases hence a current declines, current is reciprocal to resistance. Figure 4 demonstrates the plots corresponding to the examined power density.

\section{Conclusion}

In this paper an analytical model for enzymatic membraneless fuel cell with direct electron transfer was developed. The adequacy of the model was estimated by comparison with fuel cells parameters. The calculated voltage, current and power density of this model were compared with the experimental parameters. The results reveal the dependence electrical power on hydrogen ions boundary concentrations and as consequences on the rate of hydrogens ions generation and consumption, thickness of enzyme layer, enzyme concentrations, and kinetics 


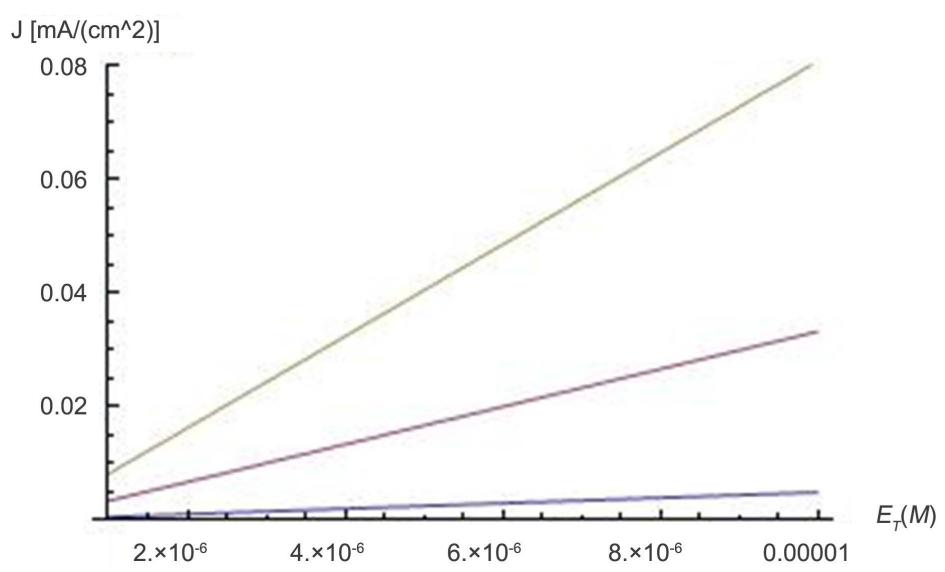

Figure 3. Hydrogen's ions current density (axis y) (Equation (19)) is plotted against total enzyme concentration (axis x). $L=5 \times 10^{-4} \mathrm{~m}$. Lines from top to the bottom glucose concentration $[G]=0.1 \mathrm{M}, 0.01 \mathrm{M}, 0.001 \mathrm{M}$ respectively. Lines from top to the bottom total enzyme concentration $E_{T}=10^{-5} \mathrm{M}, 0.5 \times$ $10^{-5} \mathrm{M}, 10^{-6} \mathrm{M}$ respectively.

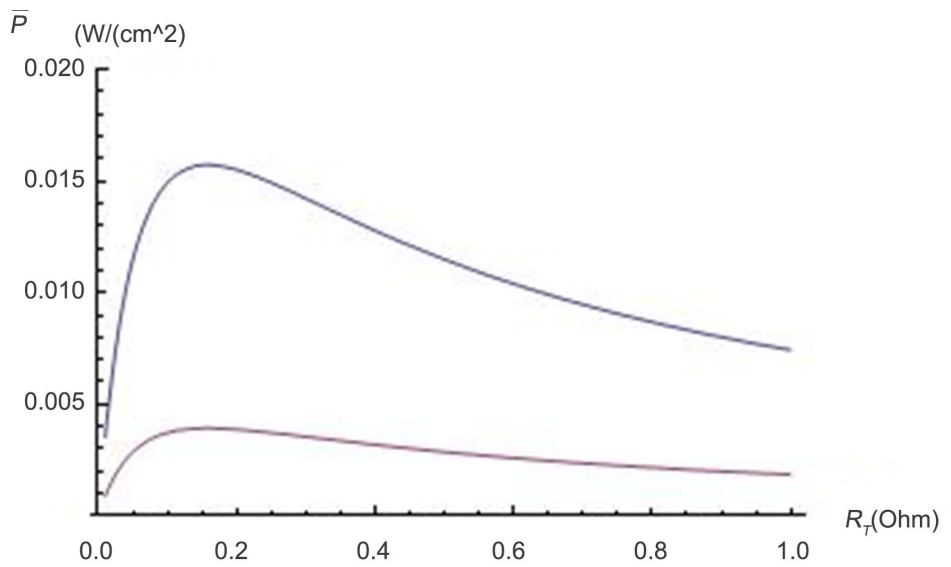

Figure 4. Power density (axis y) (Equation (24)) is plotted against external resistance $R_{L}$ (axis x) when $0.01 \mathrm{Ohm}<R_{L} .<1 \mathrm{Ohm}, r_{0}=0.16 \mathrm{Ohm}$, anode area $A=4 \mathrm{~cm}^{2}$. Lines from top to the bottom relation is $c_{L} / c_{d}=5 \times 10^{3}, 50$ respectively.

reaction rate coefficients. Hence, power can be increased with rising electrode surface. It can be achieved by increasing a porosity of electrode. Utilizing carbon nanotubes, metallic nanoparticles electrodes can significantly improve porosity. Efficient electrical communication by increasing the catalytic power of enzyme increases the rate of hydrogen ions generation and consumption, and leads to higher values of electrical parameters of fuel cell. The developed model can be used as framework for an analytic examination and an investigation of the effects of various parameters of the fuel cell to optimize a membraneless fuel cell with direct electron transfer.

\section{References}

[1] Rubin, Z. and Mor, L. (2008) Electrode Resistance Dependence on Alkaline Glucose Fuel Cell Electrolyte Concentration. Proceedings of the International Conference of Fundamentals and Developments of Fuel Cells, Nancy, December 2008, 115-116.

[2] Bubis, E., Mor, L., Sabag, N., Rubin, Z., Vaysban, U., et al. (2006) Electrical Characterization of a Glucose-Fueled Alkaline Fuel Cell. Proceedings of the 4th International ASME Conference on Fuel Cell Science, Engineering and Technology, FuelCell2006, Irvine, Vol. 2006, 8p.

[3] Mor, L., Rubin, Z. and Schechner, P. (2008) Measuring Open Circuit Voltage in Glucose Alkaline Fuel Cell Operated 
as a Continuous Stirred Tank Reactor. Journal of Fuel Cell Science and Technology, 5, Article ID: 014503.

[4] Rubin, V.(Z.) and Mor, L. (2013) Physical Models of the Conductivity in Glucose Alkaline Fuel Cell. ECS Transactions, 45, 245-257

[5] Mor, L. and Rubin, V.(Z.) (2012) Experimental and Theoretical Considerations of Electrolyte Conductivity in Glucose Alkaline Fuel Cell. Sircuites and Systems, 3, 111-117.

[6] Ge, J., Schirhagl, R. and Zare, R.N. (2011) Glucose-Driven Fuel Cell Constructed from Enzymes and Filter Paper. Journal of Chemical Education, 5, 1283-1286. http://dx.doi.org/10.1021/ed100967j

[7] Ivanov, I., Vidacovic-Koch, T. and Sundmacher, K. (2010) Recent Advances in Enzymatic Fuel Cells: Experiments and Modeling. Energies, 3, 803-846. http://dx.doi.org/10.3390/en3040803

[8] Rubin, V.(Z.) and Mor, L. (2013) Physical Modelling of the Enzymatic Glucose Fuelled Fuel Cell. Advances in Chemical Engineering and Science, 3, 218-226. http://dx.doi.org/10.4236/aces.2013.34028

[9] Shukla, A.K., Suresh, P., Berchmants, S. and Rajendran, A. (2004) Biilogical Fuel Cells and Their Applications. Current Science, 87, 425-467.

[10] Zebda, A., Gondran, C., Le Goff, A., Holzinger, M., Cinquin, P. and Cosnier, S. (2011) Mediatorless High-Power Glucose Biofuel Cells Based on Compressed Carbon Nanotube-Enzyme Electrodes. Nature Communications, 2, Article Number: 370.

[11] Fapyane, D., Lee, S.J., Kang, S.H., Lim, D.H., Cho, K.K., Nam, T.H., Ahn, J.P., Ahn, J.H., Kim, S.W. and Chang, I.S. (2013) High Performance Enzyme Fuel Cells Using a Genetically Expressed FAD-Dependent Glucose Dehydrogenase $\alpha$-Subunit of Burkholderia cepacia Immobilized in a Carbon Nanotube Electrode for Low Glucose Conditions. Physical Chemistry Chemical Physics, 15, 9508-9512.

[12] Bedekar, A.S., Feng, J.J., Krishanamoorthy, S., Lim, K.G., Palmore, G.T.R. and Sundaram, S. (2008) Oxygen Limitation in Microfluidic Biofuel Cells. Chemical Engineering Communications, 195, 256-266. http://dx.doi.org/10.1080/00986440701569036

[13] Kjeang, E., Sinton, D. and Harrigton, D.A. (2006) Strategic Enzyme Patterning for Microfluidic Biofuel Cells. Journal of Power Sources, 158, 1-12. http://dx.doi.org/10.1016/j.jpowsour.2005.07.092

[14] Jeon, S.W., Lee, J.Y., Lee, J.H., Kang, S.W., Park, C.H. and Kim, S.W. (2008) Optimization of Cell Conditions for Enzymatic Fuel Cell Using Statistical Analysis. Journal of Industrial and Engineering Chemistry, 14, 338-343. http://dx.doi.org/10.1016/j.jiec.2008.01.006

[15] Glycys, D.J. and Banta, S. (2009) Metabolic Control Analysis of an Enzymatic Biofuel Cell. Biotechnology and Bioengineering, 102, 1624-1635. http://dx.doi.org/10.1002/bit.22199

[16] Bedekar, A.S., Feng, J.J., Lim, K., Krishanamoorthy, S., Palmore, G.T.R. and Sundaram, S. (2004) Computational Analysis of Microfluidic Biofuel Cells. Proceeding of the AIChE, Austin, TX.

[17] Zebda, A., Innocent, C., Renaud, L., Cretin, M., Pichot, F., Ferrigno, R. and Tingry, S. (2008) Enzyme-Based Microfluidic Biofuel Cell to Generate Micropower. In: Drapcho, C.M., Ph Nghim, N. and Walker, T.H., Eds., Biofuel's Engineering Process Technology, McGraw-Hill, New York, 576.

[18] Pinto, R.P., Sprinivasan, B., Manuel, M.F. and Tartakovsky, B. (2010) A Two-Population Bio-Electrochemical Model of Microbial Fuel Cell. Bioresource Technology, 101, 5256-5265. http://dx.doi.org/10.1016/j.biortech.2010.01.122

[19] Weber, A.Z. and Newman, J. (2004) Modeling Transport in Polymer Electrolyte Fuel Cells. Chemical Reviews, 104, 4679-4726. http://dx.doi.org/10.1021/cr020729l

[20] Barlett, P.N., Toh, C.S., Calvo, E.J. and Flexer, V. (2008) Modeling Biosensor Responses. In: Bioelectrochemistry, Wiley, England, 267-325.

[21] Osman, M.H., Shah, A.A. and Wills, R.G.A. (2013) Detailed Mathematical Model of an Enzymatic Fuel Cell. Journal of the Electrochemical Society, 160, F806-F814. http://dx.doi.org/10.1149/1.059308jes

[22] Baronas, R. and Kulys, J. (2008) Modelling Amperometric Biosensors Based on Chemically Modified Electrodes. Sensors, 8, 4800-4820. http://dx.doi.org/10.3390/s8084800

[23] Hagen, J. (2006) Industrial Catalysis: A Practical Approach. 2nd Edition, WILEY-VCH, Weinheim. http://dx.doi.org/10.1002/3527607684

[24] eBio World: Enzyme Kinetics. www.ebioworld.com/2012/02/enzyme-kinetics.html

[25] Kuby, S.A. (2000) A Study of Enzymes. Vol. 1, CRC Press, Florida.

[26] Bard, A.J. and Faulkner, L.R. (2010) Electrochemical Methods. 2nd Edition, John Wiley \& Sons, UK. 